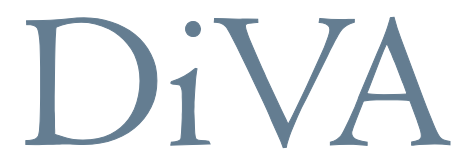

http://uu.diva-portal.org

This is an author produced version of a paper published in Solar Energy Materials and Solar Cells. This paper has been peer-reviewed but does not include the final publisher proof-corrections or journal pagination.

Citation for the published paper:

Pehlivan, I. B., Marsal, R., Niklasson, G. A., Granqvist, C-G., Georén, P. "PEI-LiTFSI electrolytes for electrochromic devices: Characterization by differential scanning calorimetry and viscosity measurements"

Solar Energy Materials and Solar Cells, 2010, Vol. 94, Issue 12: 2399-2404 URL: http://dx.doi.org/10.1016/j.solmat.2010.08.025

Access to the published version may require subscription.

Published with permission from: Elsevier 


\title{
PEI-LiTFSI electrolytes for electrochromic devices: Characterization by differential scanning calorimetry and viscosity measurements
}

\author{
Ilknur Bayrak Pehlivan ${ }^{*}{ }^{1,3}$, Roser Marsal ${ }^{2}$, Gunnar A. Niklasson ${ }^{1}$, Claes G. Granqvist ${ }^{1}$, and Peter \\ Georén $^{2}$ \\ ${ }^{1}$ Department of Engineering Sciences, The Ångström Laboratory, Uppsala University, P.O. Box 534, \\ SE-75121 Uppsala, Sweden \\ ${ }^{2}$ ChromoGenics AB, Märstagatan 4, SE-75323 Uppsala, Sweden \\ ${ }^{3}$ Department of Physics, İstanbul Technical University, Maslak, 34469 İstanbul, Turkey \\ *Corresponding Author e-mail: ilknur.pehlivan@angstrom.uu.se \\ phone: +46184713138, fax: +46184713270
}

\begin{abstract}
Polymer electrolytes containing poly(ethylene imine) (PEI) and lithium bis(trifluoromethylsulfonyl) imide (LiTFSI) can serve as model electrolytes for electrochromic devices. Such electrolytes were characterized by differential scanning calorimetry, conductivity, and viscosity measurements. The glass transition temperature $\left(T_{g}\right)$ and viscosity of the PEI-LiTFSI electrolytes have minima at a [N]:[Li] ratio of 100:1. Both $T_{g}$ and viscosity increased at high salt concentrations. The temperature dependence of the ionic conductivity and of the viscosity followed an Arrhenius equation with parameters depending only weakly on the salt concentration. The fluid behavior of the electrolytes could be reconciled with the Bingham plastic model with parameters being functions of the salt concentration.
\end{abstract}

\section{Keywords}

Polymer electrolyte, electrochromic, smart window, PEI, DSC, viscosity 


\section{Introduction}

Electrochromic (EC) devices can be used for transmittance modulation in "smart windows" [1 - 5]. The technology is of much interest for decreasing the energy expenditure in the built environment by diminishing the need for air conditioning [6], and additionally it can be beneficial for indoor comfort [7]. If implemented on a large scale, EC technology can contribute significantly to energy security and can reduce global warming, nationally [8] as well as internationally [9].

The standard EC device for "smart windows" has an electrolyte at the center. It joins two nanoporous oxide films with EC properties, typically being cathodically coloring $\mathrm{W}$ oxide and anodically coloring Ni oxide [4]. Surrounding this three-layer stack are transparent electronically conducting thin film electrodes. Optical modulation occurs when charge is shuttled between the EC oxides by the application of a dc voltage between the electrodes. Manufacturing technology is the key to practically useful "smart windows", and, in particular, the electrolyte is critical in this regard. It is applied according to one of three different strategies in EC "smart window" products and full-size prototypes, viz.

(i) the full EC device is prepared by successive depositions of five layers onto glass; here the electrolyte is an inorganic thin film, ideally giving a complete electrical separation of the EC layers

(ii) the device is fabricated in two steps, with two glass substrates each having a two layers; the two parts are joined via a slow vacuum filling process using a liquid-like electrolyte injected into a millimeter-wide gap separating the coated glasses [10], and

(iii) the manufacturing is based on two flexible polyester substrates, each having two layers, joined via lamination with a polymer electrolyte of suitable rheological properties $[4,11]$.

Clearly the mechanical properties of the electrolyte are of much interest for (ii) and (iii) [12, 13], and it may seem surprising that they have not received more scientific attention for EC technology. The present work discusses some essential properties of one particular model electrolyte.

A good electrolyte is characterized by high ionic conductivity and low electronic conductivity. Apart from being essential in EC technology, electrolytes are used in batteries, fuel cells, super capacitors, and other electrochemical devices $[14,15]$. Polymer electrolytes are formed by polymer and salt; they are advantageous with regard to flexibility, easy production, and capability to be formed as thin sheets 
for large-area applications. Poly(ethyleneimine) (PEI) is an interesting alternative for a variety of reasons, including its ability of complexing metal ions and acting as a polyelectrolyte [16]. The formation of an electrolyte with PEI is easy because of its convenient viscosity, which makes it unnecessary to use plasticizers. It is therefore a convenient model electrolyte for studies related to EC devices.

It has been suggested [14] that PEI has good solvating ability for many salts because of its structural properties; specifically PEI has sufficient spacing of the heteroatoms in the repeated chain unit due to the length of the $\mathrm{C}-\mathrm{N}$ bond and the atomic radius of nitrogen. These features lead to the formation of a suitable helical structure and easy dissolution of salts [14]. There are two types of PEI, referred to as linear, [- $\left.\mathrm{HN}-\left(\mathrm{CH}_{2} \mathrm{CH}_{2} \mathrm{NH}-\right)_{n}\right]$, and branched, [(- $\left.\left.\mathrm{NHCH}_{2} \mathrm{CH}_{2}-\right)_{x}\left(-\mathrm{N}\left(\mathrm{CH}_{2} \mathrm{CH}_{2} \mathrm{NH}_{2}\right) \mathrm{CH}_{2} \mathrm{CH}_{2}-\right)_{m}\right]$. Linear PEI is the nitrogen analogue of poly(ethyleneoxide). Nitrogen is a better donor atom than oxygen and is likely to form good complex materials when incorporated in appropriate polymer structures [14]. Branched PEI is superior to linear PEI in its ability to make homogeneous amorphous salt complexes at low salt concentrations [17].

Viscosity, ion transport, thermal stability, and conductivity are important properties for electrolytes. Electrolytes for EC applications must have moderately high ionic conductivity, convenient viscosity for applications, and thermal stability up to about $60^{\circ} \mathrm{C}$. Recent work [18] has shown that lithium bis(trifluoromethylsulfonyl)imide (LiTFSI) gives low viscosity, specifically being considerably lower than that of $\mathrm{LiClO}_{4}$.

A number of PEI-based electrolytes have already been investigated. Specifically PEI with salts of $\mathrm{Li}_{2} \mathrm{CF}_{3} \mathrm{SO}_{4}$ [16, 19-22], $\mathrm{NaCF}_{3} \mathrm{SO}_{3}$ [17, 19, 23], $\mathrm{LiSbF}_{6}$ [22], NaI [24], and $\mathrm{LiClO}_{4}$ [20, 25] - as well as with $\mathrm{LiF}, \mathrm{LiCl}, \mathrm{LiBr}, \mathrm{LiI}, \mathrm{LiSCN}$ and $\mathrm{LiBF}_{4}$ [25] - have been reported on, but we are not aware of any earlier study on the PEI-LiTFSI electrolyte.

The present work investigates thermal and mechanical properties of PEI-LiTFSI electrolytes with different salt concentration by use of differential scanning calorimetry (DSC) and viscosity measurements. DSC data were taken at temperatures between $-80^{\circ} \mathrm{C}$ and $+80^{\circ} \mathrm{C}$. The effect of the salt concentration on $T_{g}$ was studied. Measurements of viscosity and conductivity were done at a variety of temperatures and for different salt concentrations. The fluid performance of the electrolytes was analyzed. Finally the thermal and mechanical behaviors of the electrolytes were compared for different salt concentrations.

\section{Experimental}

\subsection{Materials}


Branched PEI with average molecular weight 10.000 and purity $99 \%$ was obtained from Alfa-Aesar. The Li salt LiTFSI $\left(\mathrm{LiN}\left(\mathrm{CF}_{3} \mathrm{SO}_{2}\right)_{2}, 99.95 \%\right)$ and anhydrous methanol $\left(\mathrm{CH}_{3} \mathrm{OH}, 99.8 \%\right)$ were supplied from Sigma-Aldrich and Merck, respectively. PEI was dried before use at $65^{\circ} \mathrm{C}$ and $10^{-1} \mathrm{mbar}$ for $48 \mathrm{~h}$. LiTFSI was used after drying at $150^{\circ} \mathrm{C}$ and $10^{-1}$ mbar for $72 \mathrm{~h}$. Methanol was used as received. All materials were stored dry $\left(<1 \mathrm{ppm} \mathrm{H}_{2} \mathrm{O}\right)$ in a glove box under nitrogen atmosphere.

\subsection{Sample preparation}

For the formation of the polymer electrolyte, LiTFSI was added to the methanol and stirred until it dissolved. PEI was then added to the homogeneous solution and further stirring took place. Solutions were kept at $65^{\circ} \mathrm{C}$ and $10^{-1}$ mbar for $48 \mathrm{~h}$ to remove the methanol and for drying the samples.

PEI-LiTFSI electrolytes were prepared at molar ratios of 400:1, 200:1, 100:1, 50:1, 20:1, and 10:1. The $[\mathrm{N}]$ :[Li] ratio was defined as the number of moles of the PEI repeating units, $-\left(\mathrm{CH}_{2} \mathrm{CH}_{2} \mathrm{NH}\right)$, divided by the number of moles of LiTFSI salt. The number of moles of the PEI repeating units was obtained by dividing the mass of used PEI by the molecular weight of those units $\left(43.0 \mathrm{~g} . \mathrm{mol}^{-1}\right)$. Table 1 shows molar ratios, salt concentrations, and densities of PEI-LiTFSI electrolytes used in the experiments. The density was obtained by dividing the total mass of the electrolyte, obtained from weighing, by the measured volume. The density of the electrolyte decreases with increasing salt concentration. The as-prepared electrolytes have the appearance of sticky gels.

\subsection{Characterization techniques}

Ionic conductivity measurements of PEI-LiTFSI electrolytes with different salt concentration were carried out at temperatures between $20^{\circ} \mathrm{C}$ and $70^{\circ} \mathrm{C}$, by a Novocontrol BDC-N dielectric interface together with a Solartron 1260 frequency response analyzer. The measurements were performed in the glove box under nitrogen atmosphere, using an applied ac voltage of $1 \mathrm{~V}$. The measurement cell consisted of two parallel stainless steel electrodes with diameter of $20 \mathrm{~mm}$ separated by a ring-shaped Teflon spacer with $1 \mathrm{~mm}$ radial thickness and $3.1 \mathrm{~mm}$ height. Temperatures were controlled with an accuracy of $0.5^{\circ} \mathrm{C}$ and were kept constant during each measurement. As seen in Fig. 1, ionic conductivities were in the $10^{-6} \mathrm{~S} / \mathrm{cm}$ range at room temperature and increased up to around $10^{-4} \mathrm{~S} / \mathrm{cm}$ at $70^{\circ} \mathrm{C}$.

DSC measurements were performed on a TA Instruments Q1000 Differential Scanning Calorimeter with a temperature precision of $0.05^{\circ} \mathrm{C}$. The electrolytes were first heated, then cooled, and again heated between $-80^{\circ} \mathrm{C}$ and $80^{\circ} \mathrm{C}$. Heating and cooling rates were $10^{\circ} \mathrm{C} / \mathrm{min}$ and $5^{\circ} \mathrm{C} / \mathrm{min}$, respectively.

Viscosity measurements were done ex-situ on a Brookfield DV-II+Pro viscometer with cone/plate spindle, between the shear rates 0 and $6 \mathrm{~s}^{-1}$, with a viscosity accuracy of $\pm 1.0 \%$. The cone/plate spindle 
geometry used in our experiments allowed determinations of absolute viscosity with definite shear rate and shear stress information. This geometry is very suitable for advanced rheological analysis of nonNewtonian liquids [26]. A viscometer measures the torque required to rotate a spindle in a fluid, and by changing speeds and spindles it is possible to measure in a variety of viscosity ranges. The viscosity of the PEI-LiTFSI electrolytes was studied between $25^{\circ} \mathrm{C}$ and $85^{\circ} \mathrm{C}$ with a temperature accuracy of $1^{\circ} \mathrm{C}$. For the molar ratios $20: 1$ and $10: 1$, viscosity measurements could not be performed at low temperatures because of the high viscosity of the samples.

\section{Theory}

\subsection{Fluid behavior}

Viscosity is defined as the ratio between shear stress $\tau$ and shear rate $\gamma$ and is a measure of a fluid's resistance to flow $[27,28]$. A plastic fluid behaves as a solid under static conditions and a certain force must be applied before any flow is induced. A convenient rheological mathematical model to describe a non-Newtonian fluid is the Bingham plastic model which is defined by the equation:

$$
\tau=Y_{S}+\eta \gamma
$$

where $\eta$ is the plastic viscosity and $Y_{S} i s$ the yield stress [26, 29]. A Newtonian fluid has $Y_{s}=0$.

\subsection{Temperature dependent viscosity}

The temperature dependent viscosity of a polymer electrolyte is generally described by the VogelFulcher-Tamman (VFT) equation, Eq. (2), or a relation including a temperature dependent prefactor, Eq. (3), according to

$$
\begin{aligned}
& \eta=A \exp \left(\frac{B}{T-T_{0}}\right) \\
& \eta T^{-1 / 2}=A \exp \left(\frac{B}{T-T_{0}}\right)
\end{aligned}
$$

where $A$ is a pre-exponential factor, $B$ is proportional to an activation energy, $T$ is temperature, and $T_{0}$ is related to the glass transition temperature. In a special case with $T_{0}=0$, the temperature dependence of the viscosity can be described by an Arrhenius equation, i.e.,

$$
\eta=D \exp \left(\frac{E_{a}}{R T}\right)
$$

where $D$ is a pre-exponential factor, $E_{a}$ is an activation energy, and $R$ is the gas constant. 


\section{Results}

\subsection{DSC measurements}

DSC measurements on PEI and PEI-LiTFSI were performed between $-80^{\circ} \mathrm{C}$ and $80^{\circ} \mathrm{C}$, and Fig. 2 shows data for different molar ratios. Glass transitions can be seen as small steps for all samples.

There is no evidence for melting or recrystallization. It is clear that PEI-LiTFSI electrolytes have $T_{g} \mathrm{~s}$ between $-45^{\circ} \mathrm{C}$ and $-63^{\circ} \mathrm{C}$ at different molar ratios. The estimated $T_{g}$ of PEI is $-59^{\circ} \mathrm{C}$. Adding Li salt to the polymer first decreases $T_{g}$. When the molar ratios of the electrolytes exceed 50:1, the $T_{g} \mathrm{~s}$ of the electrolytes are below the $T_{g}$ of the PEI. Between the molar ratios 400:1 and 50:1, the changes in $T_{g}$ are only 1 to $2^{\circ} \mathrm{C}$, but adding more salt causes a large increase in $T_{g}$.

Figure 3 describes $T_{g}$ versus salt concentration in detail for the PEI-based electrolytes. Clearly $T_{g}$ displays a minimum at a molar ratio of 100:1. A decrease in $T_{g}$ facilitates the motion of ions in a polymer electrolyte [30], and hence we conclude that ion motion in PEI-LiTFSI electrolytes with 100:1 molar ratio is easier than for the other molar ratios.

\subsection{Viscosity measurements}

Figure 4 shows shear stress versus shear rate of PEI-LiTFSI electrolytes at different temperatures and molar ratios. Clearly the electrolytes display non-Newtonian flow behavior. An addition of salt shifted the curves towards higher $\tau$. Because of the behavior of $\tau$ versus $\gamma$, the electrolytes were described by the Bingham plastic model.

Figure 5 illustrates the viscosity of the PEI-LiTFSI electrolytes as a function of salt concentration at different temperatures. It is apparent that $\eta$ increases with decreasing temperature for all samples. The difference of the viscosity between consecutive concentrations is highest at low temperatures. This difference decreases for increasing temperature.

The curves of $\eta$ versus salt concentration show that the viscosity increases most prominently at high concentrations for each temperature. At all temperatures, there is a minimum in $\eta$ for electrolytes with molar ratio 100:1. Generally the decrease in the viscosity can be understood as a consequence of higher mobility. This result is consistent with the concentration dependence of $T_{g}$ in Fig.3.

Figure 6 shows that the yield stress goes up somewhat with increasing salt concentration. The difference between the subsequent values of $Y_{s}$ versus salt concentration is higher at $85^{\circ} \mathrm{C}$ than at the other temperatures.

Comparing the data in Figs. 3, 5, and 6, it is evident that $\eta, Y_{s}$, and $T_{g}$ display the same dependency upon changes of the salt concentration. Specifically, all of these properties increase when the salt concentration goes up. All of these properties change less at low concentrations than at high ones. Furthermore, $\eta$ and $T_{g}$ increase more at molar ratios below 50:1 than at ratios above this value. 
Enhanced values of $\eta$ and $T_{g}$ upon increasing salt concentration lead to a drop in the segmental flexibility of the polymer chain [31], and hence our data point at a significant decrease of this flexibility below the molar ratio 50:1.

The temperature dependence of the viscosity was fitted by the VTF equation, but in each case we found that $T_{0}$ was not significantly different from zero. Hence the temperature dependence is of Arrhenius type (Eq. 4). Figure 7 shows that data on $\ln (\eta)$ versus inverse temperature indeed display linear relationships and the correlation coefficients for the fittings were in all cases better than 0.996. Reliable activation energies were not found for the 20:1 and 10:1 samples because they could not be measured at the lowest temperatures. The Arrhenius parameters, $D$ and $E_{a}$, are listed in Table 2 for different molar ratios. It is seen that the activation energy does not depend significantly on the salt concentration. It is also very similar to the activation energy of the ionic conductivity, as obtained from the data in Fig. 1.

\section{Discussion and Conclusion}

PEI-LiTFSI electrolytes were characterized by DSC and viscosity measurements. The electrolytes were found to have a glass transition between $-45^{\circ} \mathrm{C}$ and $-63^{\circ} \mathrm{C}$ at different molar ratios, and they were thermally stable above these temperatures. Adding salt firstly decreased $T_{g}$ and then increased it drastically. The electrolytes had minimum $T_{g} \mathrm{~S}$ at the molar ratio 100:1, showing that ion motion is easiest at this molar ratio.

The fluid behavior of the electrolytes was characterized via the Bingham plastic model. Rheological parameters showed that the flow behavior changed with the salt concentration. The viscosity increased at higher concentrations. A minimum of the viscosity at 100:1 points at facile ion motion at that molar ratio. It is also concluded that the molecular mobility of the electrolytes exhibits a considerable decrease for molar ratios below 50:1. The yield stress displayed some increase with salt concentration. The parameters of the Bingham plastic model and $T_{g}$ showed a similar behavior with regard to concentration. The temperature dependence of the viscosity was well described by an Arrhenius equation; the parameters of this equation were rather independent of the salt concentration.

The present work has demonstrated that PEI-LiTFSI electrolytes combine a number of properties that make them interesting for applications in laminated electrochromic devices [4, 11], and the work serves as a starting point for more in-depth studies. 


\section{Acknowledgements}

This work was partially supported by a grant from the Swedish Research Council for Environment, Agricultural Sciences and Spatial Planning (FORMAS). The authors would like to thank Dr. Tim Bowden for making his laboratory available for the DSC measurements and Prof. Jöns Hilborn for useful discussions. One of the authors (İ.B.P.) gratefully acknowledges Prof. Fatma Tepehan for making this scientific collaboration possible and İstanbul Technical University for financial support.

\section{References}

[1] C.G. Granqvist, Handbook of Inorganic Electrochromic Materials, Elsevier, Amsterdam, 1995.

[2] C.G. Granqvist, Electrochromic tungsten oxide films: Review of progress 1993-1998, Sol. Energy Mater. Sol. Cells 60 (2000) 201-262.

[3] C.G. Granqvist, E. Avendaño, A. Azens, Electrochromic coatings and devices: Survey of some recent advances, Thin Solid Films 442 (2003) 201-211.

[4] G.A. Niklasson, C.G. Granqvist, Electrochromics for smart windows: Thin films of tungsten oxide and nickel oxide, and devices based on these, J. Mater. Chem. 17 (2007) 127-156.

[5] C.G. Granqvist, Transparent conductors as solar energy materials: A panoramic review, Sol. Energy Mater. Sol. Cells 91 (2007) 1529-1598.

[6] E.S. Lee, S.E. Selkowitz, R.D. Clear, D.L. DiBartholomeo, J.H. Klems, L.L. Fernandes, G.L. Ward, V. Inkarojrit, M. Yazdanian, Advancement of Electrochromic Windows, California Energy Commission, PIER, Publication number CEC-500-2006-052 (2006).

[7] R.D. Clear, V. Inkarojrit, E.S. Lee, Subject responses to electrochromic windows, Energy. Buildings 38 (2006) 758-779.

[8] B. Richter, D. Goldston, G. Crabtree, L. Glicksman, D. Goldstein, D. Greene, D. Kammen, M. Levine, M. Lubell, M. Savitz, D. Sperling, F. Schlachter, J. Scofield, J. Dawson, How America can look within to achieve energy security and reduce global warming, Rev. Mod. Phys. 80 (2008) S1S107.

[9] UNEF, Buildings and Climate Change: Status, Challenge and Opportunities, United Nations Environment Programme, Paris, France, 2007.

[10] C. Xu, C. Ma, X. Kong, M. Taya, Vacuum filling process for electrolyte in enhancing electrochromic polymer window assembly, Polymers Adv. Tech. 20 (2009) 178-182.

[11] A. Azens, G. Gustavsson, R. Karmhag, C.G. Granqvist, Electrochromic devices on polyester foil, Solid State Ionics 165 (2003) 1-5. 
[12] Bauer, S., Bronstert, B., Möhwald, H., Neuss, M., Burkhardt, U., Optically transparent polymeric solid electrolyte, US patent 6,361,709 (2002).

[13] Elkadi, Y., Agrawal, A., Holdmann, T., Electrochromic safety glazing, US patent 6,639,708 (2003).

[14] J.R. MacCallum, C.A. Vincent, Polymer Electrolyte Reviews-1, Elsevier Applied Science, London and New York, 1987.

[15] M. Armand, W. Gorecki, R. Andreani, Proceedings of the Second International Symposium on Polymer Electrolytes, Siena, Italy, 1989, Elsevier Applied Science, Amsterdam, 1990.

[16] J.-L. Paul, C. Jegat, J.-C. Lassègues, Branched poly(ethyleneimine)- $\mathrm{CF}_{3} \mathrm{SO}_{3} \mathrm{Li}$ complexes, Electrochim. Acta 37 (1992) 1623-1625.

[17] C.S. Harris, M.A. Ratner, D.F. Shriver, Ionic conductivity in branched polyethylenimine-sodium trifluoromethanesulfonate complexes. Comparisons to analogous complexes made with linear polyethylenimine, Macromolecules 20 (1987) 1778-1781.

[18] M. Deepa, N. Sharma, S.A. Agnihotry, S. Singh, T. Lal. R. Chandra, Conductivity and viscosity of liquid and gel electrolytes based on $\mathrm{LiClO}_{4}, \mathrm{LiN}\left(\mathrm{CF}_{3} \mathrm{SO}_{2}\right)_{2}$ and PMMA, Solid State Ionics 152-153 (2002) 253-258.

[19] S. York, R. Frech, A. Snow, D. Glatzhofer, A comparative vibrational spectroscopic study of lithium triflate and sodium triflate in linear poly(ethylenimine), Electrochim. Acta 46 (2001) 15331537.

[20] R. Tanaka, T. Fujita, H. Nishibayashi, S. Saito, Ionic conduction in poly (ethylenimine)- and poly (N-methylethylenimine)-lithium salt systems, Solid State Ionics 60 ( 1993 ) 119-123.

[21] B. Unal, R.J. Klein, K.R. Yocca, R.C. Hedden, Influence of DGEBA crosslinking on $\mathrm{Li}^{+}$ion conduction in poly(ethyleneimine) gels, Polymer 48 (2007) 6077-6085.

[22] S.S. York, M. Buckner, R. Frech, Ion-polymer and ion-ion interactions in linear poly(ethylenimine) complexed with $\mathrm{LiCF}_{3} \mathrm{SO}_{3}$ and $\mathrm{LiSbF}_{6}$, Macromolecules 37 (2004) 994-999.

[23] C.S. Harris, D.F. Shriver, M.A. Ratner, Complex formation of poly(ethylenimine) with sodium triflate and conductivity behavior of the complexes, Macromolecules 19 (1986) 987-989.

[24] T. Takahashi, G.T. Davis, C.K. Chiang, C.A. Harding, Chemical modification of poly(ethylene imine) for polymeric electrolyte, Solid State Ionics 18\&19 (1986) 321-325.

[25] C.K. Chiang, G.T. Davis, C.A. Harding, T. Takahashi, Polymeric electrolyte based on Poly(ethylene imine) and lithium salts, Solid State Ionics 18\&19 (1986) 300-305.

[26] http://www.brookfieldengineering.com/download/files/more_solutions.pdf (2009). 
[27] C.K. Schoff, Recent advances in the rheology of high solids coatings, Progr. Org. Coating. 4 (1976) 189-208.

[28] G.M. Kavanagh, S.B. Ross-Murphy, Rheological characterisation of polymer gels, Progr. Polymer Sci. 23 (1998) 533-562.

[29] http://www.glossary.oilfield.slb.com (2009).

[30] V.S. Kolosnitsyn, G.P. Dukhanin, S.A. Dumler, I.A. Novakov, Lithium-conducting polymer electrolytes for chemical power sources, Russ. J. Appl. Chem. 78 (2005) 1-18.

[31] I. Albinsson, Dielectric and Conductivity Studies of Polymer Electrolytes, Unpublished PhD Thesis, Chalmers University of Technology and University of Gothenburg, Sweden, 1994. 


\section{Figure Captions}

Figure 1. Salt concentration dependence of the ionic conductivity for PEI-LiTFSI electrolytes at different temperatures.

Figure 2. DSC curves of PEI and PEI-LiTFSI electrolytes at the shown molar ratios.

Figure 3. Salt concentration dependence of the glass transition temperatures $T_{g}$ of PEI-LiTFSI electrolytes with the indicated molar ratios.

Figure 4. Shear stress versus shear rate for PEI-LiTFSI electrolytes with various molar ratios at different temperatures, (a) $25^{\circ} \mathrm{C}$, (b) $45^{\circ} \mathrm{C}$, (c) $65^{\circ} \mathrm{C}$, and (d) $85^{\circ} \mathrm{C}$.

Figure 5. Viscosity versus salt concentration of PEI-LiTFSI electrolytes at the shown temperatures.

Figure 6. Yield stress versus salt concentration of PEI-LiTFSI electrolytes at the shown temperatures.

Figure 7. Viscosity versus inverse temperature $T$ of PEI-based electrolytes at the shown molar ratios. Symbols are measured viscosity data and straight lines are fits to the Arrhenius equation.

\section{Table Captions}

Table 1. Molar ratios, salt concentrations, and densities of PEI-LiTFSI electrolytes.

Table 2. Arrhenius parameters, $D$ and $E_{a}$ as defined in Eq. (4), and glass transition temperature $T_{g}$ of PEI-LiTFSI electrolytes at the shown molar ratios. 


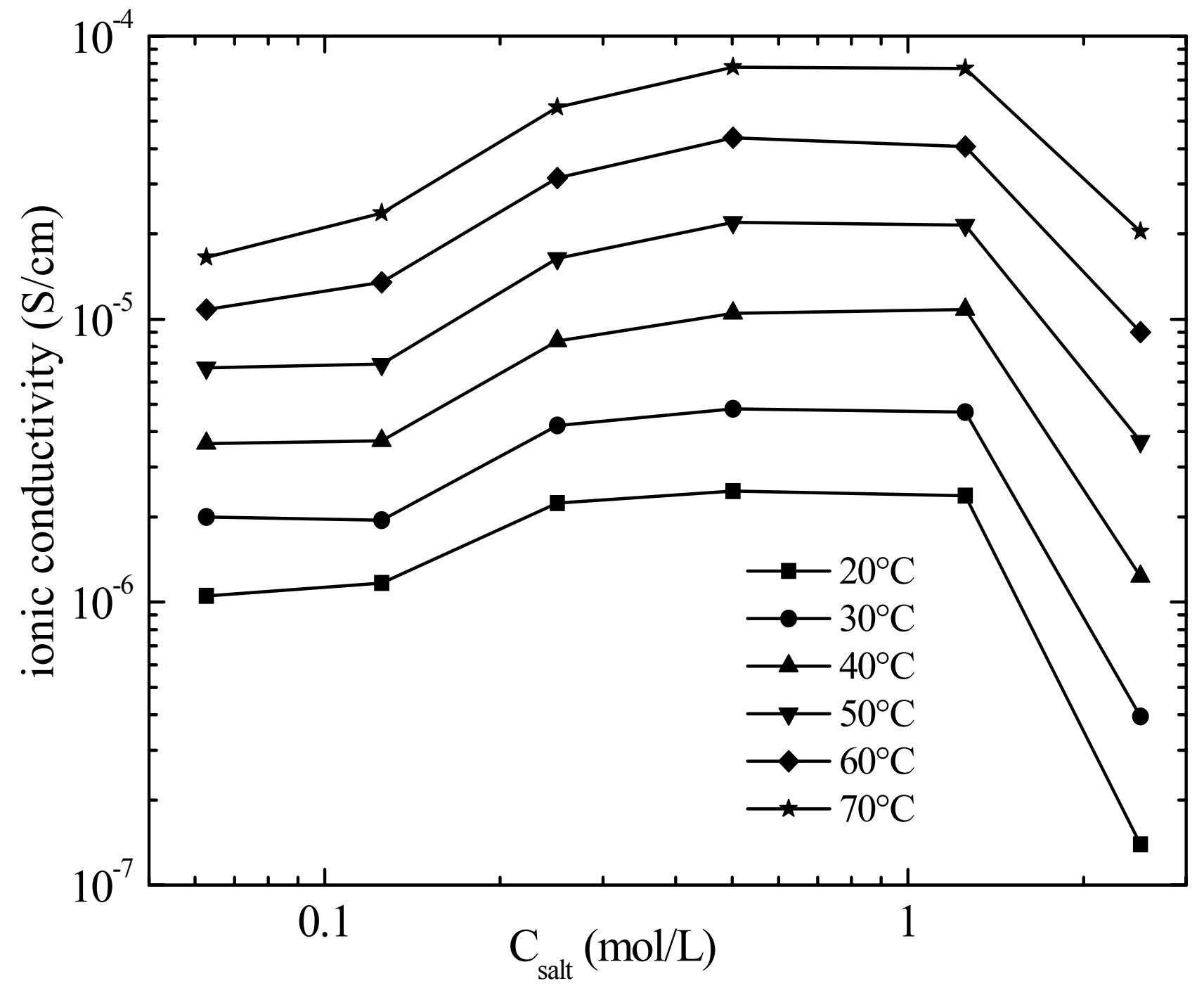

Figure 1 


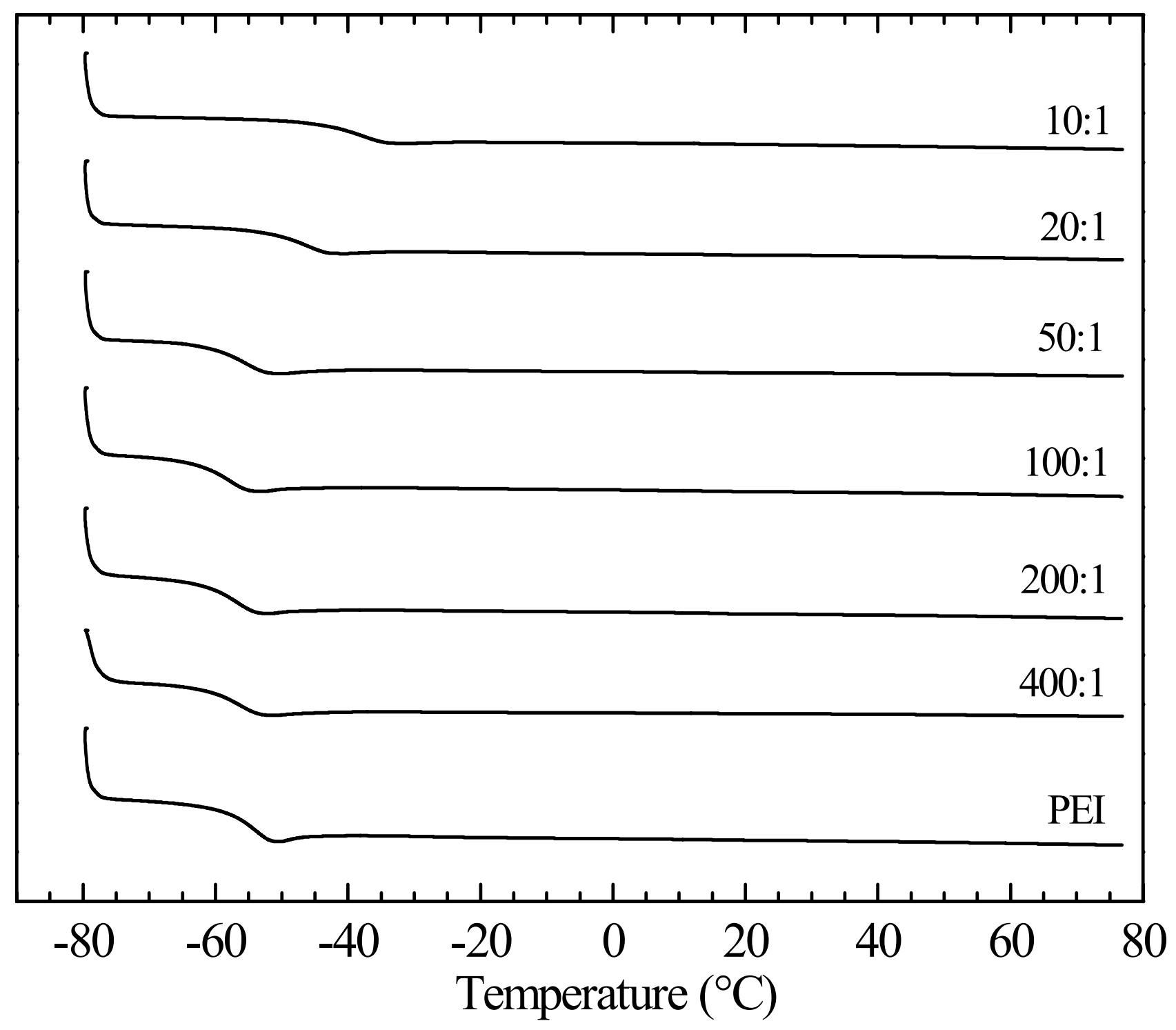

Figure 2 


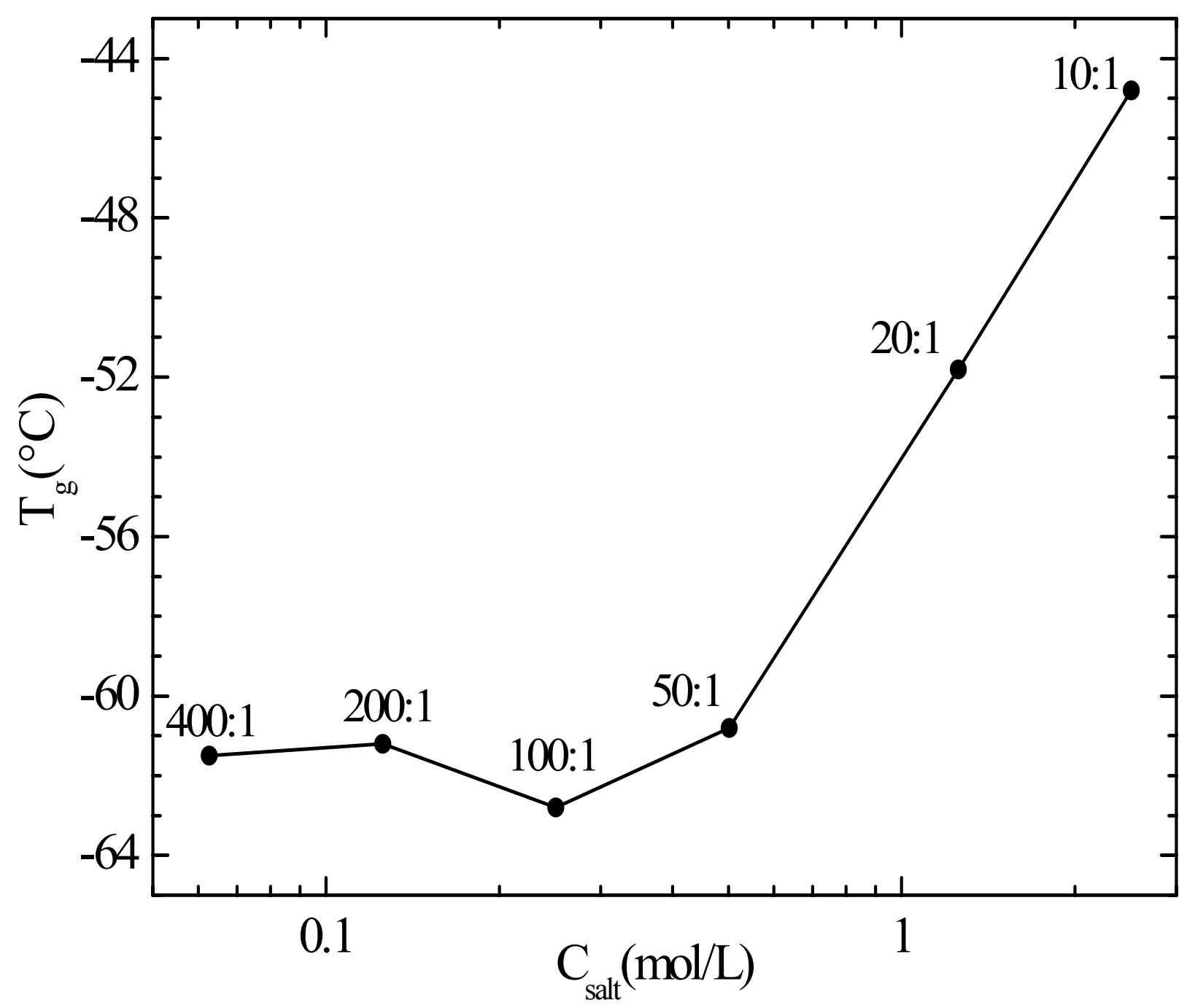

Figure 3 

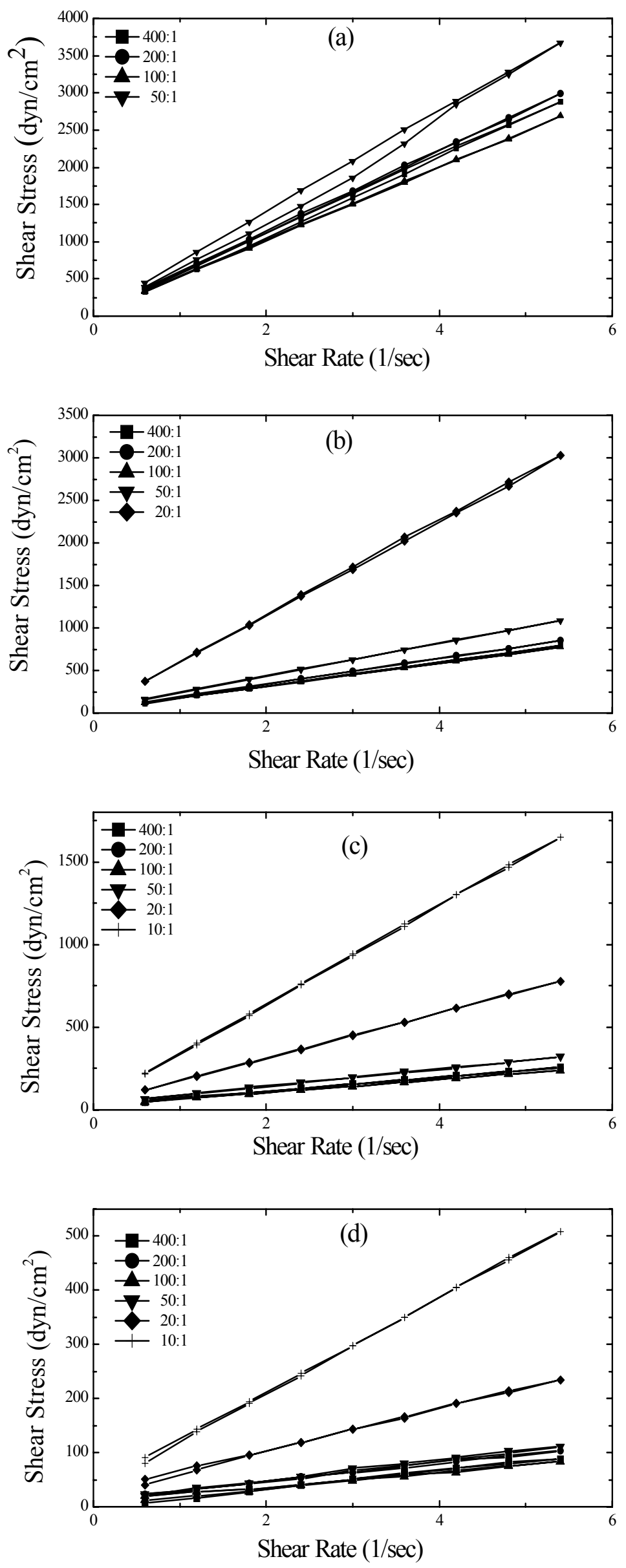

Figure 4 


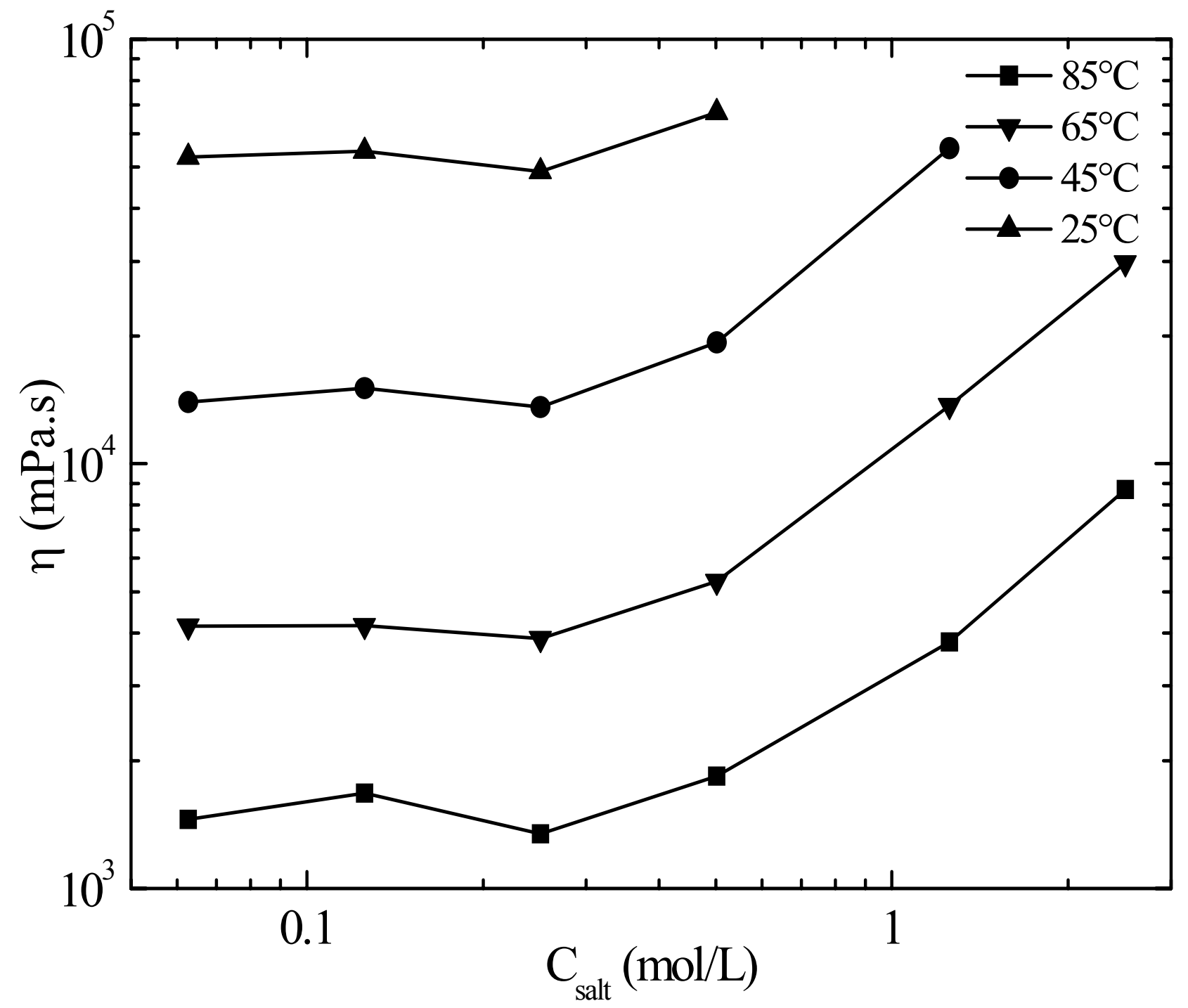

Figure 5 


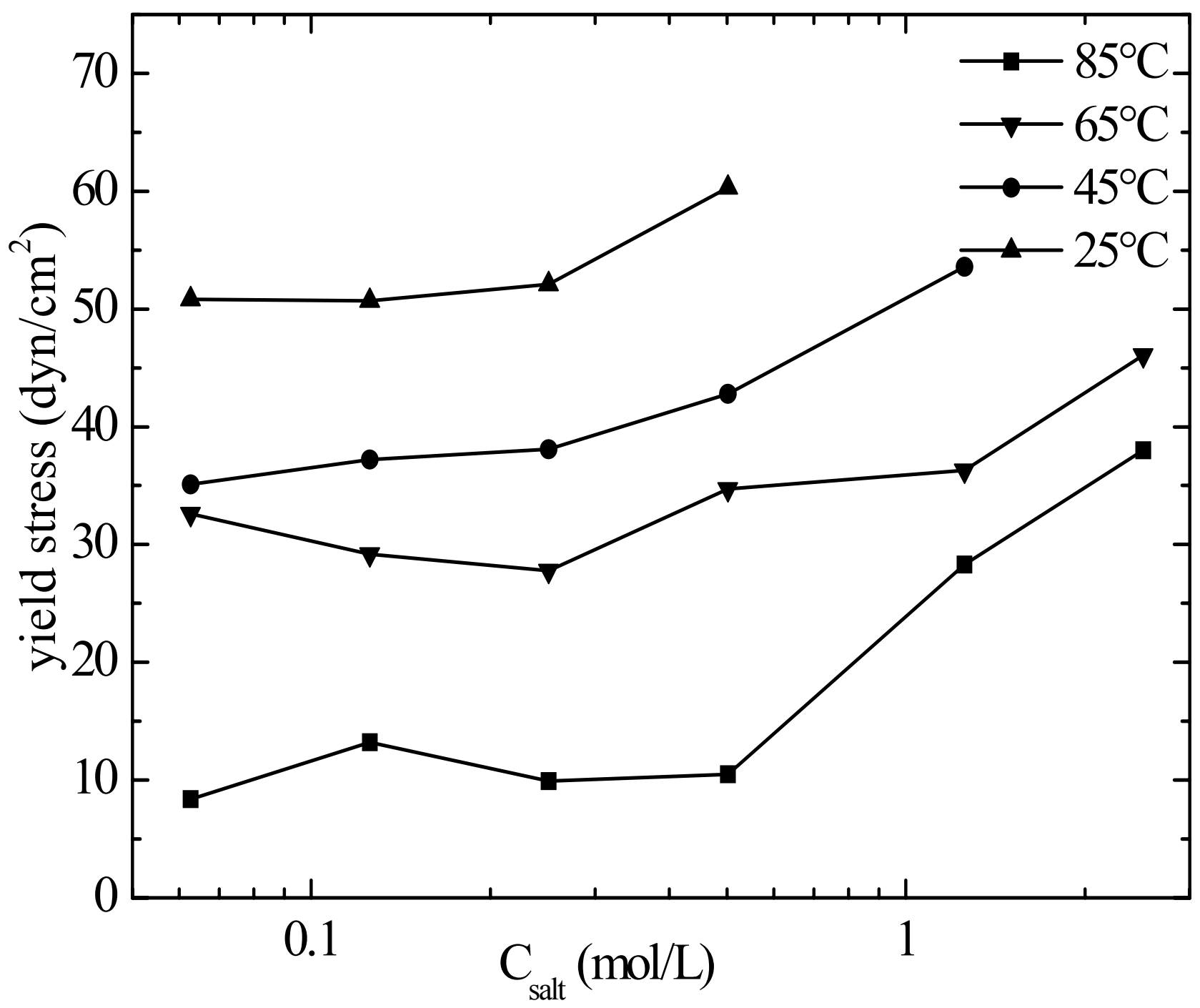

Figure 6 


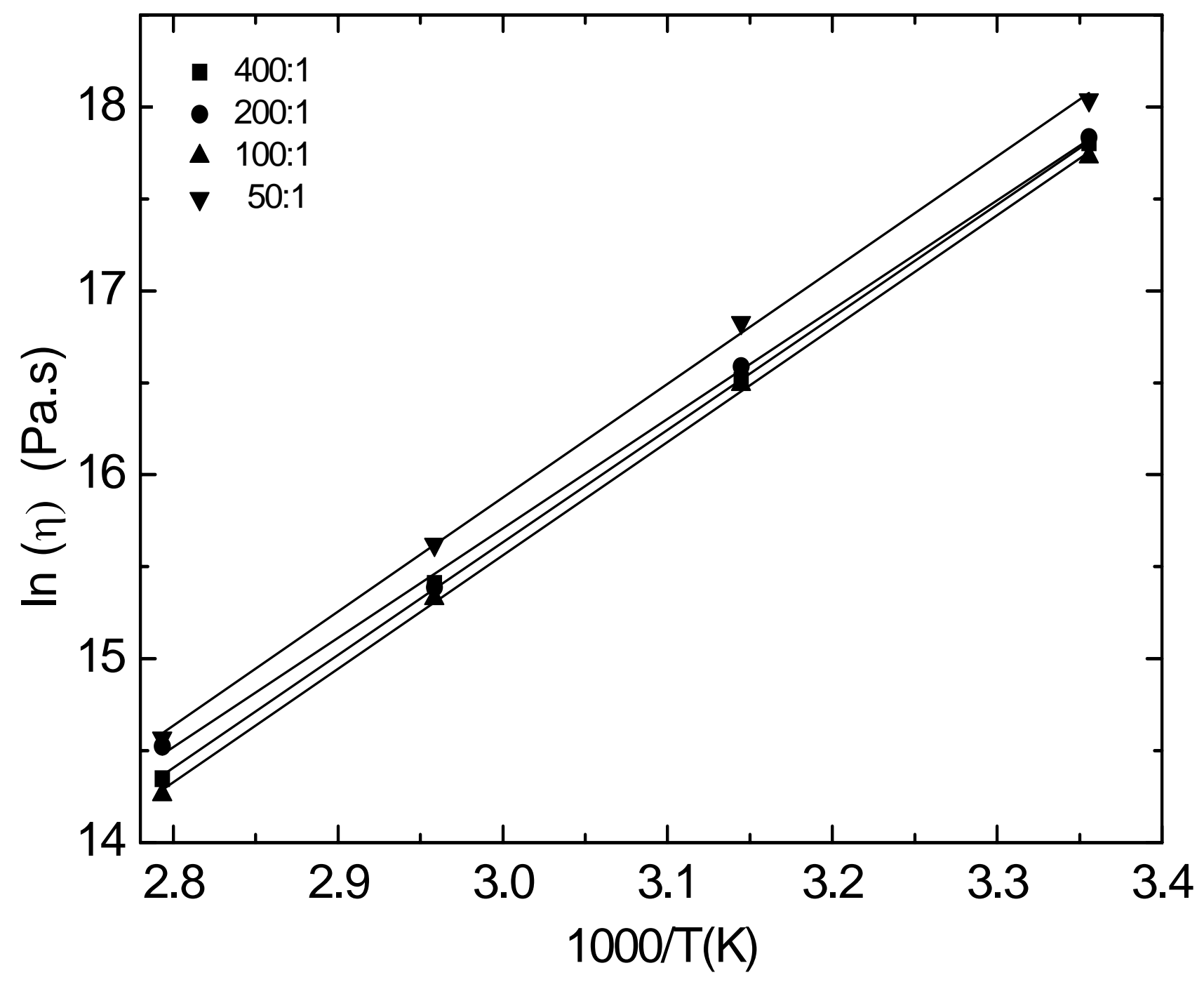

Figure 7 
Table 1.

\begin{tabular}{lll}
\hline$[\mathrm{N}]:[\mathrm{Li}]$ & $C_{\text {salt }}(\mathrm{mol} / \mathrm{L})$ & Density $(\mathrm{g} / \mathrm{ml})$ \\
\hline 400 & 0.06 & 1.10 \\
200 & 0.13 & 1.07 \\
100 & 0.25 & 0.93 \\
50 & 0.50 & 0.86 \\
20 & 1.25 & 0.78 \\
10 & 2.51 & 0.72 \\
\hline
\end{tabular}

Table 2.

\begin{tabular}{lllll}
\hline$[\mathrm{N}]:[\mathrm{Li}]$ & $T_{g}\left({ }^{\circ} \mathrm{C}\right)$ & $T_{g}(\mathrm{~K})$ & $D(\mathrm{~Pa} . \mathrm{s})$ & $E_{a}(\mathrm{~kJ} / \mathrm{mol})$ \\
\hline 400 & -61.5 & 211.5 & 0.06 & 50.93 \\
200 & -61.2 & 211.8 & 0.12 & 49.44 \\
100 & -62.8 & 210.2 & 0.05 & 51.27 \\
50 & -60.8 & 212.2 & 0.07 & 51.47 \\
20 & -51.8 & 221.2 & - & - \\
10 & -44.8 & 228.2 & - & - \\
\hline
\end{tabular}

